ontbindende Chlor vermittelst einer Arhre in die Säure so lange zu liciten, bis alle schwofelige Sïure zersetat ist. Die Salzsäure ist frei von schwefeliger Säure, wenn ein Tropfen der Chlorverbindung augenblicklich die Farbe des Indigs, die derselben ertheilt worden ist, zeretört, und frei ron Chlor, wenn sie für sich diese Farbe nicht rerändert.

(Annaies de chimie et do physique Nov, 1835)

\title{
Ueber die Herstellung der Zündkraft der Platinschwarmmchen;
}

von Dr. Friedrich Mohr in Coblenz.

Dis Iraft des Platins verschiedene Gasarten miteinandor zar Verbindung zu reranlassen, beruht auf dem wesentlichen Umstand der Reinheit der Obcrfläcbe dieses Metalles, und siv kommt demselben, wie Fa rada gezeigt hat, unter allen Gestalten als Dratb, Platte oder Pulrer zu. Was aber Reinheit der Oberfläche bedeute, ist ebenfalls dorch denseltuen zuerst bestimmt ausgesprochen worden. Das Abwischen der Platinplatte, welche als + Pol der Säule gedient hatte, rait der roinsten Leiviwand verrichtet diese Figenschaft volllommen Es lag nui sehr nahe was bei den Platinschwömmchen allmählioh dio Zündhraft vernichten müsse. Dio Form des Schwammes ist ron : illea die günstigste um diese Erscheinung herrorzubringen, nicht nur weil sie die grofste Obernäche darbietet, sondern anch weil der innere Theil des Scluwammes ror jeder Berïhrung, und somil auch ror jeder Verunreinigung geschützt ist. Jedoch die blofse Bcrührung der atmosphäriachen Luft wirkt sehr vermindernd und zulotal fost vernichtend auf diese Eigenschaft, wahrscheinlich 
weil in derselben Btofit als feino Stäubchen rerbreitet sind, welche sicb auf das Platin ablagern and dadnroh seine Ober fäche beschmotzen. Da diece Stoffe vio der qewöbnaliche Zimmerstanb jedoch grofsentheils organiscber Natur aind, ron den Mleidern, Möbeln, Fufrböden, Tapeten u. \& w. abgestofse⿰, vo werdon sie durch Glïhen gröfotentheils zerstört, vod die Zündkraft dee Schwämmcbons wieder hergestellt. Jedoch ist diefs nar palliativ; diese Stoffe hinterlassen et. was Ascbe, und beim oftern Ausglüben bleibt die Zündluraft immer mehr geschwächt. Es war noch we versuchen ob die Methode wolche Faraday mit so vielem Erfolg boi Platimplatten angewandt hat, nicht aoch in diesem Falle gute Dienste leisten bönne, und diese wahrscheinliche Voraussetzurg hat sich volltommen bewäbrt. Eine Anzabl ron Platinochwämmchen welche an ihrer Zündkraft hedentend verlowen hatten, wrordon in einem Porcellanschälchen odex einem Platintiegel mit reiner concentrirter Schwefelsäure übergunsoo, und $1 / 4$ Stunde lang bis zum Irampfen der Sebwefelaciure erwäent, denn erkalten gelassen, dio Echwefelsäure abgegosen, ond frisch destillirtes Wasser anfgegossew. Hasselbe wurdo zum Hochen erwärmt, abgegossen, durch neues eretzt, und diese Operation 4 bis 5 mal wio. derholt, his das Platinschwömmchen nafs auf ein Lacmaspapier gelegt die Stelle nicht im geringsten mehe rörhete. Nach dem Irocknen hatte das Echwämmchen seine vollhommene Zündhraft wieder erlangt. Die Entzündung des Wasserstoff's geschieht durch diese Schwämmchen so rasch und mit solcher Verpuffung wie vermittelst des Eloctiopbors. Trochnet man die Schwefelsäure, statt sie auss.o. waschen, auf dem Schwämmchen durch eine Weingeistlammo aus, 60 ist dio 'Lünatkraft des Schwämmehens ganz vernichtet. Fine Substanz ron so trïffiger Atfinität wio die 8chwo- 
foluäure nimmt in Glas - oder Porcellangetafsen immer so viel Stoffe (Kali, Natron, Kalk) ouf, um nach dem Verdampfen eine beschmutzende 6ohichte so hinterlasen, ob. gleich ansere Heagontien dieselben eben 80 wenig, wie die Spuren der abwischenden Loinwand entdeclien honnen. Bai den Platinschwämmohev tritt aber noch eine Voranlassung dnzu, welche ihre Hraft sohr bodeutend vermindern ja sogar gund rernichten bann. Beim Anflösen des Zinkes in rem dünnten Säuren wird ron jedem Gasbläıohen welches aufcteigt ein n̈afserst feines 'I'heilehen ron der Flümigleit in die Hothe gevorfen, welches so zart ist, dafs es ron dor Luft gotragen and wreggefübrt wird, und sich nur sehr langsum aus dercielben absetzt. Es ist behannt dafs das Wassorstoffgas in: diesem unreinen Zastande Niefsan erregt, and zwar nur durch dio fortgeführtea Theilohen ron sohwefelsaurem Zink. Bei einer sehe sarken Antlosung wonnte ioh des schwefelenure Zink, obschon an sioh nicht flüchtis ist, anf eine Entfernung ron 6 bis 8 Fufs deutlich riechen. In dor atmosphärischen Laft trockneu diese Tröpfeben, wie das Meerwasser bei der Brandang, aus, und das Salzstäabchen kann no so leichter fortgeführt werdeo. Diefo letztere tritt zwar in der Zündlampo nicht ein, allein boim Oeffnen des Hahm werdeu diese noch feucbten Tröpfichen gegen das Schwämmchen getriebon, haften an demselben, and vermindern seine Zïndbraft. Durch nachheriges Glühon unter Zwtritt von freiem Wacserstoff wird der schwefolsaure Zink erst in das basischo Salz $A$ f fredson's verwandelt, und nachher durch die zogleich wirkende Affinität des Platins allmäblig zu Zink redncirt, welches sich mit dem Platin verbindet; dasselbe zum sintern bringt, und alsdann sehr bald scine fraft vollkommen zerstört. Ich habe solche Schwämmclsen erhalton, welche so hart waren dal's sie Politur annahmen, sich 
hämmern liefsen, wobei sie sich jedoch sprüder als reines Platin zeigten. Dio Quantität Jes Zinkes kann aulserordentlich gering seyn, so dafs seine Prennung rom Platin und Nachweisung vielleicht Schwierigiteit haben hönnte.

1.)ie Behandlung des Schwämmohens mit concentrirter Schwefelsäure und Auswaschang nimmt dicse Schichte bosisch schwefelsouren Zinkes weg, the sie reducirt worden ist, und rcrleiht dem Schwämmchen aufser gröfseler Zündkraft auch löngere Dauer.

Aufser diescr Behandiungsweise der Schwämmchen dic ich bei dem allgemein verbreiteton Gebrauche der Platinlampen für eincn wilihommenen Beitrag halte, will ith noch auf folgende Hleinigkeiten aufmerksäm machen. Bei der Bereitung der 8chwämmchen müssen die Substanzen frei von tenerbestïndigen Stoffen segn, besondere von lfali; es darf ulso auch nur sublimirter Salmiak angewendet werden. Da aber die Süuren, während der heifsen Aullüsung des Platins inmer etwas Kali aus dem Gefülse aufnehmen tö̈nen, so kann sich auch etwas Chlorplatinbalinm bilden, welches zwar in der Flüssigkeit aufgelöat bleiben Hann, bei der nachherigen Fällung aber durch Flächenenzichung mit niedergerissen wird and beim Ausglühen Chlorkalium zurüchläfst. Es ist nicht vortheilhaft den Platinsalmials selbat anozuwaschen, wegen seiner Löslichlseit, und weil das Chlorplatinkalium doch zurück. bleibt, dagegen ist es zwechmäfsig, unmittelbar nach dem Ausglühen die Schwämmchen der angefïhrten Behandlung xu unterwerfen, weil sie in jedea Falle an Zündkraft zunehmen. Nan bewahre die Schwömmchen nicht in Schächtetchèn und Baurowolle, sondern in einem festrerschlosecnen Glase, oder was noch leichter und sicherer ist, unter Wasserverschlufs, durch cin darïber gestürztes in Wasser tauchendes Gefïls. Man gebrauche die Lompen, wo möglich, nicht während der Auflösung des Zinlies oder gleich darauf, sondern erst nacb 
einiger Zcit, was in Allgemeinen ron selbst sich ereignet. Dic Bedechung der Schwămmehen darch cinen Decliel ist sehr angurathen, und es wirde hiex ein Wasservergnhlufs gewils siles mogliche teistin.

\section{Ueber Papierfabrication aus Torf; von $\boldsymbol{R}$. Mallet.}

Dio hier in Rede steheade Torfart hommt unmittelbar nnter der Dammerde aller Niederungon oder Sümple in Irland, häıfig in 13 Fufs mächtigen Lagem ror. Sie besteht aus Blättern und Stengeln vcrsehiedener Hoose und au Fasem und Warzeln zahlreicher Wasser - und Sumpfptlanzen u. s. w. Die Fasern aind hart, und haber meiatens ihre uroprüngliche Form vollsommen beibehalten; sie sind mehr oder weniger regelmälsigg in parallelen Schichten gelagert, die Farbe ist braunroth und das spec. Gew. variirt awischea $0,360-$ 0,650 .

Man achlug ror, nus den gebloichten Fasern Papier zu machen, indem man sie entweder allein dozu benutzte odor die verschiedenen Substanzen damit ersetste, die man jetzt als Surrogate des Lcinenpapiers anwendet, wie Ifalk, Gyps, Thon, Banmwolle, Haare, Lederabfïlle, Hopfenschöfslinge u. s. w.

Sie eignen sich aufserdem noch im ungebleichten $\mathrm{Zn}$ stande zn einem vorzüglichen Pappendeckel, wonn man sie binlänglich macerirt, ausprefst und mit Auflözungen von Leim, Melasse, austrocknenden Oelen, Harz und ähnlichen andern Substanzen behandelc. Der so bearboitete Pappendechel hält chr gut die Einwirkung ron stark orhitztem Dampfe aus.

Im feuchten Zustande enthält diese Torfart 3 bis 4 Proc. feuerfeste Bestandtheile, und in loIttrockenen 4-6 Proc. 